

\section{Employer Supported Volunteering Programs in Large Corporations}

\section{Introduction}

The term Social Economy has been used for years to describe a segment of the economy that is neither driven by the profit motives of private interests, nor owned by the state to serve public interests. Often referred to as the third sector, (distinct from the private for-profit sector and public sector) it defies clear boundaries (Moulaert \& Ailenei, 2005). Thus definitions of the social economy vary. In the US the term social economy is not used at all; there the third sector refers strictly to organizations that adhere to the non-distribution-of-profits rule stipulated by the US Internal Revenue System (Graefe, 2006). In Quebec, the term Social Economy has been in use for several decades, but refers to a partnership between state and third sector organizations and an exercise in stemming the tide of neo-liberal globalization (Graefe, 2001). In Ontario and the rest of Canada, reference to a Social Economy is more recent and the concept is applied in a broader manner, in keeping with some European notions of the Social Economy (Fonatan \& Shragge, 1997). This broader conceptualization eschews strict adherence to non-distribution stipulations and includes cooperatives and social enterprises in addition to nonprofit organizations.

Irrespective of the boundaries of the Social Economy, there is general agreement that the Social Economy is that sector of society made up of private, non-governmental organizations whose abiding purpose is social in nature even though they participate in economic activities such as employment, financial transactions, property acquisition or leasing, pensions, trading, and the like. This common conceptualization of the social economy is based on an organizational perspective; indeed, most of the disagreement in definitions stem from what types of organizations are to be included or excluded in the term.

In contrast, the perspective of this chapter is to view the social economy in terms of activities (rather than organizations) aimed at enhancing the "the social good" in communities and society. Thus certain activities within the public and corporate spheres might also be considered as part of the social economy. In fact, part of the State's mandate is to provide for the good and welfare of its citizens and it may do so in a variety of ways. When the government partners with nonprofits to provide social services and achieve social goals, then the "public sector" is indirectly contributing to the social economy. Over the years, the corporate sector too has been taking an interest in promoting "social good". This may be the result of several trends: increasing demands by the public to see large corporations "give back" to their communities 
(Berger et. al 2006); government legislation requiring corporations to prepare annual Public Accountability Statements (PAS); and tax reforms more favourable to charitable giving. Thus, when a corporation partners with a nonprofit organization by making donations or collaborating with them in other ways, it is promoting and in a sense participating in the social economy. Foster and her colleagues (Foster, Meinhard, Berger \& Krpn, 2008) have identified three levels of corporate involvement in Canada's social economy: sporadic and short-term, with little expectation of long-term benefits to their own organizations; self-beneficial, when corporations sponsor social economy organizations primarily to benefit their own organization through enhanced brand recognition; and finally, socially beneficial, when corporations' philanthropic goals are motivated by a genuine desire to improve society by establishing long-term partnerships and joint ventures with social economy organizations. At all of these levels, corporate contributions to the social economy may be purely financial, expressed in the form of donations and/or ongoing financial partnerships, or they may involve active participation in the social economy through voluntary activities undertaken by employees, mostly on company time, and occasionally through employee secondments to nonprofits for longer term assignments.

In this paper we focus on the voluntary contribution of employee time and related activities, and present findings from research we conducted in 2006 to examine employer supported volunteering programs in Canada's large financial institutions. Before describing our research, we present a brief history of the involvement of Canadian corporations in philanthropic activities and a literature review of employer supported volunteering in Canada.

\section{Corporate Philanthropy}

Although research on corporate philanthropy dates back only to the 1930's and 1940's (Carroll, 1999), company donations were no doubt common in the days when businesses were locally owned and employers and employees participated together in community events. With mass transportation and the advantages of economies of scale, local businesses were replaced by large national corporations that were remote from and less involved in the communities they served (Kleiner, 1996). In the 1960's many US corporations established philanthropic foundations in the belief that Corporate America had an obligation to the communities they served (Smith, 1994). By the late 1970s and early 1980s, America was witnessing a surge of "corporate social responsibility" in the form of charitable donations and the development of long-term partnerships with nonprofit organizations (Sinclair and Galeskiewicz, 1997). This trend occasioned Nobel Laureate economist Milton Friedman to state that "there is one and only one social responsibility of business--to use its resources and engage in activities designed to increase its profits so long as it stays within the rules of the game" (The New York Times Magazine, September 13, 1970). It appears that a majority of organizations took heed; despite a 
slight increase in overall corporate contributions to social and cultural projects, this increase was not proportional to the growth of the business sector as a whole (Sagawa \& Segal, 2000). Despite the lip-service paid to corporate social responsibility only $30 \%$ of commercial organizations in the United States contribute to social, cultural, educational and other causes (KPM \& Peat Marwick, 1997).

In Canada, corporate philanthropy has developed more slowly and is not as widespread as in the US. This may be attributed to two reasons: a historically strong partnership between government and the nonprofit sector (Tucker, Singh, \& Meinhard, 1990), and comparatively speaking, very meager tax exemptions for donations (Azer, 2003). Until the closing decade of the twentieth century, the Canadian nonprofit sector was reaping the benefits of a social welfare program in which government partnered with nonprofit agencies to extend specialized services to its citizens (Tucker, Singh, \& Meinhard, 1990). With steady funding from government for arts and cultural programs as well as for social service organizations (Meinhard, 2002), there was little need for support from the corporate sector. Thus the culture of corporate giving was less highly developed. And, because of meager tax exemptions (Azer, 2003), low participation continued even as government funding for social services was being sharply reduced (Hall \& Banting, 2000) and nonprofit organizations were looking for support from the private business sector to fill the gap (Foster \& Meinhard, 2005).

Corporate culture is slowly changing as Canadian businesses are facing increased shareholder demands for greater involvement in finding solutions to Canadian and global social problems (Pinney, 2001; Schmid \& Meinhard, 2000). In an attempt to increase corporate involvement in the social economy, the Canadian Centre for Philanthropy (now Imagine Canada) launched their Caring Company Program in 1988, which, among other things, asks corporations to: "commit a minimum of $1 \%$ of pre-tax domestic profit to support charitable and nonprofit organizations and encourage and facilitate the personal giving and volunteer activities of our employees" (Imaginecanada.ca/caring Companies Commitment.pdf (click here)). Currently, 120 corporations are enrolled in the program (ibid).

Additionally, in 2001 legislation was passed requiring all financial institutions with over $\$ 1$ billion in equity to submit Public Accountability Statements (PAS) annually (Government of Canada, 2001 fcac-acfc.gc.ca/rights/public). Bill C-8 requires banks and all other financial institutions [with equity of $\$ 1$ billion or more] to publish an annual statement detailing the contributions of the institution to the Canadian economy and society (cancrc.org/recomm). These programs seem to have had an impact: corporate giving among Imagine members has almost doubled, increasing from $.064 \%$ of pre-tax profits in 1988 to $1.04 \%$ in 2000 (Imagine Canada, 2002), and corporate donations now make up $3 \%$ of the total revenue in the nonprofit sector, up from $1 \%$ in 2002 (Muttart Foundation, 2002). 
This is still far below the level of individual donations (8\%) and government support (49\%) (NSNVO, 2005).

Financial support is only one way in which large corporations are increasing their involvement in the social economy. Programs to encourage and support employee volunteering are becoming more prevalent worldwide, and in Canada as well.

\section{Employer Supported Volunteering}

Employer supported volunteering (ESV) - variously called corporate volunteering programs or employee volunteering programs - refers to a range of initiatives provided by employers to encourage and support community volunteering among their employees. According to Linda Graff (2004, p.6), "ESV can range from simple acknowledgement that employees

perform volunteer work in the community, through to ongoing staff time-off and in-kind support of community efforts and charitable causes."

\section{Examples of Employer Supported Volunteering}

Following are some examples of ESV initiatives mentioned in the Canadian literature:

- Providing information: e.g. liaising with local volunteer centres, creating a web site (Easwaramoorthy et al., 2006).

- Giving recognition: e.g. honouring volunteers at special events, awards for exemplary community work, rewarding volunteers by donating to their organization of choice often referred to as "Dollars for Doers" (Carpenter, 2004; Graff, 2004).

- Providing resources: e.g. allow volunteers to use company equipment or facilities for their programs. (NSGVP, 2004)

- Giving time: e.g. modify work hours or give time off for volunteering projects, allow secondments to nonprofit organizations. (NSGVP, 2004)

- Organizing teams: e.g. organize employee committees to encourage volunteering in special events (Rog et al., 2004)

- Sponsoring events: e.g. special runs/walks etc, and encourage employee participation (Hall et al., 2007).

- Forming partnerships: e.g. long-term partnerships with community agencies to share expertise through employee volunteers (Rog et al., 2004). 


\section{Benefits}

With the exception of a few studies (e.g. Peloza et al., 2008; de Gilder et al., 2005, Lee, 2001; Merrill \& Safrit, 1998), most of the ESV literature, both in Canada and abroad, is either descriptive or prescriptive, with the general aim of making a business case for corporate volunteering programs Mostly the articles either just intuit the benefits that would accrue from ESV programs or quote organizational officials. Basically, making the business case links ESV first and foremost to competitive advantages in terms of external stakeholders: customers, clients, investors; and internal stakeholders, the employees.

- External stakeholders. Because the volunteers are out in the community representing their organizations, they are like organizational ambassadors and help:

○ increase brand recognition (Graff, 2004; Points Of Light Foundation, 2005; Hall et al., 2007);

- improve client relations and enhance customer loyalty because of the personal contact, and also because of the reputation (Graff, 2004; Rog et al., 2004; Points Of Light Foundation, 2005);

- provide feedback to their organizations about community needs for new product development (Graff, 2004; Points Of Light Foundation, 2005);

- enhance the organization's reputation to attract investors (Points Of Light Foundation, 2005);

- increase goodwill towards the organization which provides them additional opportunities for further community involvement (Points Of Light Foundation, 2005);

- create stronger communities, which in the long run provide a more stable base for businesses (Hall et al., 2007).

- Internal Stakeholders. Most of the focus in the literature in making the business case revolves around the attraction, recruitment and retention of employees, skills improvement, and increased productivity.

- Companies with good community involvement records are able to attract and recruit the most talented people (Rochlin \& Christopher, 2000; Hall et al., 2007).

- ESV improves employee satisfaction, loyalty, team spirit and morale, thus decreasing turnover rates of employees (Graff, 2004; Hall et al., 2007; Rog et al., 2004; Points Of Light Foundation, 2005; Peloza \& Hassay, 2006; Easwaramoorthy et al., 2006).

- ESV provides opportunities for enhancing existing skills and acquiring new ones (Graff, 2004; Rog et al., 2004; Points Of Light Foundation, 2005; Peloza \& Hassay, 2006). 
- With high satisfaction and morale, and improved skills sets, productivity is also increased (Graff, 2004; Rog et al., 2004 et al., 2004, P\&H, Easwaramoorthy et al., 2006war).

These benefits are the main motivational thrusts for setting up employee volunteer programs, however Hall and his colleagues found that several of their respondents reported that "their companies contributed to charities and nonprofit organizations primarily because of their philanthropic commitment to communities" (Hall, et al., 2007 p. 9). Several articles (e.g. Peloza \& Hassay, 2006; Graff, 2004) also mention benefits that accrue to the employee volunteer beyond the general benefits that result from volunteering: career advancement; workplace recognition; meeting other employees; work variety; and new knowledge and skills transferable to the workplace, especially "people skills". However, these benefits are not universally achieved in all ESV programs. Peloza and colleagues (2006, 2008) demonstrate that volunteer credit programs like "Dollars for Doers", (i.e. programs that give a monetary reward to the organization in which the employee volunteers) do not afford the individual or the company as many benefits as volunteering done in company teams for a specific cause or organization adopted by the company.

Finally, some articles (Graff, 2004; Rog et al., 2004; Peloza et al., 2008) mention the benefits gained by community agencies. In a time of decreasing intensity of volunteer participation (NSGVP 2004), the benefits to the voluntary sector of ESV are significant. ESV programs provide access to reliable and motivated volunteers often with skills that match their needs. The exposure of these employee volunteers to nonprofit agencies may also lead to new individual donors, increased corporate donations, greater public awareness of their cause, and referrals for other prospective volunteers. Peloza and his colleagues (2008) found that there was a strong likelihood that employee volunteers would continue to volunteer with the agencies even after the official corporate program was over. Thus ESV contributes to a broader volunteer base for nonprofit organizations.

\section{Challenges}

Beyond the benefits, these programs also pose challenges both to the corporation and to the community agency. Covering the workload for volunteers was the most commonly mentioned challenge among 990 business surveyed; almost one quarter of organizations saw this as a problem (Easwaramoorthy et al., 2006). Responding to requests and juggling multiple stakeholder expectations with limited staff and resources were reported to Hall and his colleagues in their study (Hall, Easwaramoorthy \& Sandler, 2007). Rog and her colleagues (2004) found that the cost of participation, time to administer programs selling the program to 
employees, lack of good models, and adjusting to the expectations of community agencies, were the key challenges mentioned by the 34 ESV program directors in their sample.

\section{Prevalence of ESV in Canada}

In 2005 Imagine Canada underwrote a survey to gauge the extent of support from Canadian business for employee volunteering. The subsequent report (Easwaramoorthy et al., 2006), indicates that informally, more than $70 \%$ of Canadian businesses support their employees' volunteering efforts in some manner, however only $14 \%$ have a formal volunteer program supported by company resources. Support of employee volunteering is demonstrated in many different ways. The authors note that "the most common forms of support are adjusting work schedules (78\%); providing time-off without pay (71\%); and allowing access to company facilities and equipment (70\%)" (Easwaramoorthy et al., 2006, pg. iii). Fifty-eight percent of businesses provide financial or in-kind support to nonprofit organizations where their employees volunteer, but only a few businesses encourage volunteering by organizing volunteer recognition events $(35 \%)$; actively providing information about volunteer opportunities $(31 \%)$ or providing paid time off $(29 \%)$.

\section{Methodology}

This research focuses on employer-supported volunteering among Canada's financial institutions in the banking and insurance industries. These institutions have been at the forefront of corporate social responsibility and community involvement often serving as models for other organizations (Foster et al., 2008). In this study, we are interested in understanding the motivations for the programs they undertake, with a particular focus on ESV programs. We examine the structure of these programs, how they fit into the overall corporate strategy and how these activities can be perceived as contributing to the social economy. To this end, we were guided by the following research questions:

- What types of ESV programs are offered and how they are run?

- What is the reason for encouraging employee volunteering?

- What are the benefits to the employer and employee?

- Have ESV programs generated an increase in volunteering?

- How do employees perceive their contribution?

- What are the opportunities and challenges faced by employer and employees?

- What are the successful and not successful experiences of ESV programs? 
As we are also interested in employee experiences with, and attitudes towards ESV programs, we surveyed employees of one of the institution to understand employee perceptions and motivations. We present the findings of this survey as a case study at the end of our findings.

\section{Sample}

We contacted all financial institutions with Public Accountability Statements (PAS) that indicated ESV programs. Of these eleven institutions, eight agreed to be interviewed: Canada's five major banks, and three of the large insurance institutions.

\section{Data collection}

Interviews were arranged with each of the responding organizations, at a time and place of their convenience. With the exception of one interview, conducted over telephone, the interviews took place in corporate offices and lasted from an hour to an hour and a half. The interviews were semi-structured to cover the research questions listed above. In some cases, more than one representative of the institution was present,

For our case study, a survey questionnaire was constructed with the collaboration and assistance of the officer in charge of the ESV program at her institution. The survey examines the demographic profile of the employee volunteers, describes their volunteering activities both outside of their institution, and through the ESV program of their institution, probes their motivations for volunteering in the two situations. The survey questions were mainly forcedchoice, closed-ended, however opportunities for elaboration and comments were made available. The survey was administered on an independent platform accessed through the company's internal website between May-August 2007. It was directed at all 3000 employees in the institution's head office. Almost three hundred employees completed the online survey. Although this represents a small fraction (10\%) of the total number of employees, we believe that this low response rate might be a factor of conducting the survey during summer months when employees might have been on vacation. Of the 299 respondents, 272 [90.9\%] had volunteered with support from the Company's ESV program the 12 months prior to the survey between August 2006 and August 2007.

\section{Data analysis}

The interviews were transcribed, and the transcriptions were coded to maintain confidentiality. After transcription, they were analyzed and themes were identified. The questionnaire results were analyzed and open ended, qualitative questions were content coded. 


\section{Findings}

\section{Types of programs}

The overall impression gained from the interviews was the general similarity of the types of ESV programs offered in these institutions, even though the details often differed. The programs can be broadly categorized as: a) volunteer credit programs, sometimes referred to in the literature as inter-organizational volunteering, and b) institutional (in-house) projects, sometimes referred to in the literature as intra-organizational volunteering.

Credit for volunteering is a highly valued part of ESV programs. These credit programs are designed to recognize and encourage volunteering efforts (ranging from $25-50$ hours a year) of their employees by donating a sum of money (ranging from $\$ 250$ - \$1500) to the nonprofit organizations at which the employees volunteered. The program is based on the popular American "Dollars for Doers", although only one of our respondents named it as such. The high priority of these programs is indicated by the fact that it was usually the first one mentioned when respondents were asked to describe their ESV programs

All the institutions run this program on a basis of trust, with the applying employee asked to nominate a nonprofit organization at which he or she volunteered for at least the number of hours (25-50) required to be eligible for the award. There is no requirement to show proof of the number of hours volunteered. However, most institutions have clear guidelines with respect to the kinds of nonprofits they are ready to support. In at least two institutions, this program extended to volunteering in family units.

When asked whether there is a monetary cap on the program, the common answer was either that there is no official cap or that there are specific sums budgeted for the program. However as one respondent explained:

"It was recently explained to me that it wasn't really a cap, it was more of a start-up budget given to the program. It is hard to say what we would expand to." [1]

In any event, none of the respondents experienced a situation in which volunteers were denied their reward because of lack of funds. In fact, several respondents indicated that they are happily ready to pay out much more than they presently do, if only more employees would take advantage of the program. Not everyone eligible for receiving credits applies for them.

"I'm not sure even what a reasonable goal is. I haven't looked into it enough, but to me 4\% [of employees] seems low, and I'm sure if our employees started using it [applying for 
credit] we'd move up to $10 \%$ or whatever. The company would continue to pay that amount, well I would hope." [6]

"We know that we are now undertaking to more broadly communicate it internally, because, while a number of employees do know about it, we know that more employees work in the community and they have not yet applied for funding through it." [4]

This feeling was shared by all the respondents. And, although information about the program is available on the internal employee website, there are no systematic strategies in place to advertise or market this program. Some respondents feel that knowledge of the program is spread mostly by word of mouth. All respondents would like to see higher participation rates and feel that their communication strategies can be improved.

Respondents do not think that these credit-for-volunteering programs actually encourage employees to go out and volunteer more. They see it as a way to reward employees for the volunteering they are already doing on their own time and outside of the work environment.

"I think it's a bit more of an after-the-fact recognition...especially with this program, where they're doing it on their own time. Who are we to? We are giving them some money in recognition, but they're the ones putting in the time and the sweat work, right?" [3]

At the same time, the institution garners visibility in the community, as the cheque presentation ceremony is accompanied by some form of internal and external publicity.

Institutional projects, as opposed to the credit-for-volunteering program, refer to volunteering efforts engaged in institutionally, either at the initiative of the employees, or as part of the overall philanthropic strategy of the organization. Both of these are characterized by forming teams of employee volunteers at their place of work. These team efforts are more likely than individual volunteering, to be accompanied by time off work as they are often run during the week in working hours. Employee generated programs most often occur at branch levels, and do not necessitate approval or oversight from the officer in charge of employee volunteering or corporate philanthropy at the head office.

"Our belief has been that we need to let our staff in local communities get behind whatever is passionate to them. So for me to sit here in Toronto and say, 'thou will volunteer for [such and such] ... Maybe cancer isn't the biggest issue in your community, and maybe the biggest issue in your community is, I don't know, the SPCA. Why should they not be able to fundraise for that in their local community? So, we purposefully have left it quite decentralized... There is the distinct feeling that we should not be driving the agenda, they need to get behind what they want to get behind. "[2] 
They are often single event fundraising drives earmarked for a certain cause or helping in specific community projects by contributing time. The kinds of fundraising activities and which community organizations are supported is left to the discretion of the branch manager, as long as the organization's general guidelines are followed. The institution will often contribute towards the efforts of their employees by promising to match funds, at least until a certain threshold is reached.

"And our executives are very strongly supportive of the localized community reach of it, and the grassroots reach that it gets us. That "grassroots" word, it becomes a buzzword. The team put on some sort of fundraising initiative. It can be a barbeque in the branch parking lot, it can be a golf tournament that they organize, they can participate in a walka-thon for MS, whatever, and walk as a team. If they do those things, the monies that they raise are matched by the bank." [2]

Although most of the employee initiated volunteering projects focus on fundraising, there are definitely other types of volunteer activities, for example in one institution, employees took:

"a day of their time to build Habitat homes... so they go out for the day and build for a day...again, subject to their managers approval." [7]

Direct volunteering, as opposed to volunteering to help raise funds, is more often initiated at the institutional level rather than the employee level, or in response to requests from nonprofit agencies. These initiatives are part of a broader partnership established with other organizations. Examples of this are mentoring programs or providing expertise to nonprofit organizations in specific areas such as HR or financial management, or tutoring for youth at local schools. These "expertise partnerships" may be expressed in the form of lectures or workshops, or one on one counseling delivered at regular intervals or on an "as needed" basis. Some of these partnerships involve secondments, where the employee actually joins the staff of the nonprofit organization for a specified period of time. For example, an employee joined the United Way for a year to help its management team, anther was seconded to a nonprofit organize a major fundraiser. Environmental cleanups

\section{ESV program administration}

Each of the institutions had different arrangements for the administration of the program, but with the exception of two institutions, ESV was not an important part of the organization's corporate philanthropy strategy. In these two institutions, one of the officers championed ESV programs, but these efforts were the result of their personal commitment to ESV rather than a corporate policy. The low priority of the ESV program is exemplified by the fact that in many 
institutions ESV is peripheral to the main focus of the department that houses it, be it Human Resources, Public Relations, Corporate Social Responsibility, Community Relations, etc. Furthermore funds allocated to ESV programs were never fully utilized.

In the two organizations with ESV champions, the program was well developed, with many different options available for employees to participate in. In most cases it was impossible to determine the rate of volunteering because of a lack of systematic tracking of volunteers or their participation, especially at branch levels, where much of the volunteering takes place. For instance, although our respondents knew how many volunteer credit cheques were issued, they did not have any numbers on individuals participating in institutional projects requiring volunteer time. Furthermore, even when individuals volunteered on their own, the institutional incentives to reward or encourage them were not taken advantage nor were these hours reported anywhere mostly due to the lack of information on the part of the employees. Because records were not kept, our respondents could only estimate the rate of volunteering through institutional projects; this ranged from ranged from $10 \%$ to "pretty much the national average".

One of the most consistent findings was the ineffectiveness of communication strategies in promoting volunteer programs.

"When we do employee volunteer initiatives, the only challenge we have is in the communication... While we can communicate corporately, through website, internal email...because there are so many businesses in the [institution] it's often hard to keep what employees want [outside the main office], and they don't always follow national methods." [1].

The programs run at the branches, or initiated in departments were much more successful as they relied on word-of-mouth dissemination among much fewer employees with a strong emphasis on team building amongst them.

"Again it varies within each office... we're not dealing with great numbers of individuals, so there's a different dynamic that occurs in the field offices, it depends on the size, the nature of the office, whether or not they hold monthly meetings, it can be as simple as that." [8]

The institutions in our sample strongly supported these team building efforts as they see direct benefits of this in building employee morale. Therefore, it seemed to us that the institutions were more ready to be flexible in giving employees time off to do these volunteer activities than in giving similar benefits to those doing volunteering on an individual basis.

"They would, in fact, maybe get together and have a morning of, who knows, some training, development, or some aspect of their business? And then they might, for a 
couple of hours, sort of late in the afternoon or whatever portion of the day, they might go out and do something.... in supporting community-based organizations. "[4]

None of the institutions had time -off policies for individual volunteering, however all of them said such time-off was negotiated between the individual and his or her manager and it was done on an ad hoc basis. Three respondents said their institutions promoted such a culture even in the absence of formal policy.

"I don't think that there's a specific policy saying if you're volunteering for a charity, you can take time off. But I know [our company] is really good on flex hours, and that's you know you get your work done, you come in a little early and leave a little early as long as you're getting your work done and its basically up to you or your manager. [6]

\section{Working for the social good}

In this section we examine the motivations of both the institutions and their employees for engaging in community projects that involve volunteer activities on the part of their employees.

Institutional perspective. From the above we see that the institutions are willing to support many employee related activities that promote the social good. During our conversations it was clear that these efforts carry with them some explicit and implicit costs. For example, this includes costs of the direct monetary donations to match their employees fundraising and volunteer efforts, as well as the employee time involved in organizing and volunteering in institutional projects.

"The team put on some sort of fundraising initiative. It can be a barbeque in the branch parking lot, it can be a golf tournament that they organize, they can participate in a walk-a-thon as a team. If they do those things, the monies that they raise are matched by [the company]. " [2]

In addition, the costs include the staff time of many of our respondents in disseminating, promoting and managing such programs. At the time of the interviews, respondents were unable to share the actual costs of these programs, although they admitted that such costs were real but difficult to estimate as they were embedded among other programs related to corporate philanthropy or public relations. The benefits on the other hand, were easily accounted for, albeit in a qualitative manner with no monetary estimates on these benefits. These benefits, perceived or otherwise, gave us insights into why these institutions may be interested in supporting activities that contribute to the social good. 
There are three main categories of benefits as related by respondents. These are employee related benefits, benefits that accrue to their business, and benefits to the social economy. Among the employee related benefits, our respondents emphasized those that build employee morale and as well as goodwill towards and pride of their employer.

"What has been most important to me is the surge in employee pride in the organization....this is certainly a very important part of what do but I don't necessarily think there has been an enormous surge of recognition in the community. But I really think it is a point of pride for the employees. " [1]

They also speculated that their programs would make it easy for them to recruit good candidates as well as help them in employee retention.

"I think we can safely say that it has been a point of attraction for potential employees. Just the general data available to us completely supports that." [1]

"I can't say whether or not we've recruited more employees because of this... [but] I think with respect to volunteerism, it does help in recruiting. I think people want to work for an organization that has certain social responsibilities and corporate citizenship. But I think that recruiting would be important, also retention. I think there are a whole lot of important things that a company can realize through contributions. Also, as a resident in the community, and I think the corporation also benefits when community organizations benefit. When you talk about the corporation, that's in everyone's interest, having a strong healthy community. And as a stakeholder, that's a good thing. "[ 4]

Business related benefits included the visibility that ESV programs gave their institution among the local agencies, community organizations and the public at large.

"We get all kinds of things... high profile in lots of small communities and [it is ] very important." [5]

"The way we engage our people [in ESV] made it very, very obvious they recognize us. So, it's a tremendous validation and endorsement. It is the whole aspect of our corporate citizenship and what we do in communities across Canada is part of our recruitment kit." [8]

But some pointed out that recognition was not the most important gain.

"This is certainly a very important part of what we do, but I don't necessarily think there's been an enormous surge in recognition in the community. But I really think it's a point of pride for the employees. " [1] 
Others clearly indicated that they were not in it for the recognition.

"It's about doing good for the sake of doing good. I don't discount companies who profile themselves or who do press releases or put their logos on things. They have reasons. Some of them are business reasons and some of them make a lot of sense, but for us, for our business, we don't need to do it. And I'm proud to work for a company that has such a strong brand, that we don't need to do that'. [7]

In all, these ESV programs do help enhance their image as good corporate citizens especially at a time when many of these institutions are declaring record breaking profits and the public is increasingly demanding some social accountability from them. None of the respondents thought that the new legal requirement to publish a Public Accountability Statement was a driving force in these programs.

"I don't think the PAS is driving it. I think word-of-mouth of our staff is driving it.”[2]

Be this as it may, the individuals we interviewed recognized the need for corporate social responsibility and saw it as their mission to help their institutions contribute to the social economy. From our interviews, we find that many of the institutions in our sample had a strong culture of philanthropy, but fewer had a culture of community engagement.

"Well, maybe what I should say at the outset is that it's [ESV] hugely important for us, corporately, to not only acknowledge the wonderful work that our employees are doing but to encourage that in our corporate culture. And it speaks to the values of the organization, so it is hugely important." [3]

There is a sense among our respondents of the importance of their commitment to the social economies of the communities they serve and they see their ESV programs as one way of achieving this and thereby directly engaging and contributing to the social economy, as one respondent said

“Philanthropy is really about building communities.” [4]

Individual Perspective. From the institutional perspective, employees participating in ESV programs are seen as "ambassadors to the community" and in this sense not only bringing benefits to their institutions but engaging in the production of social goods. To examine whether individuals who participate in volunteering activities in these institutions see themselves as being motivated to enhance the "the social good" in their communities we examine the responses of the survey conducted with employees in one of the institutions in our sample, whom we refer to as the Company for reasons of confidentiality. 
The survey was conducted, as described in the methodology section, to ascertain some o of the benefits and motivations of employees engaged in ESV programs. For example, we want to know to what extent are they responding to their employer's expectations of being 'good' employees and participating in activities promoted by their company How much of their activities are perceived as coercion versus voluntary.

We note that for all individuals participating in such programs volunteering is at some point a personal choice. For most volunteers it is argued that there is a cost of supplying unpaid labor for a social good. Although there are many intangible benefits that accrue to the volunteer, the act is one where the costs exceed the benefits and hence the individual is considered a volunteer (Handy et al, 2006). Consider a volunteering activity that takes place at the individual's own discretion at his or own time at a personal level versus a similar activity done at the individual's discretion but to which he reports to his company. In this case it is not unreasonable to argue that the benefits to the individual for reporting his activity to the company are greater, in terms of career enhancement, or being perceived as a 'good' employee, a team member and so on. This is especially true if the company seeks to promote such activity among its employees and uses it in its publications on corporate social responsibility. Lowering the net costs to the individual suggest this would increase the amount of volunteering done and hence promote growth in the social economy. By examining why individuals choose to get involved in such activities might shed light on whether this method of promoting the social good is indeed an important way we can rethink of corporate /nonprofit partnership in the social economy.

Before we embark on the findings and discussion of this survey, we present the context of the survey respondents can choose to volunteer. The Company had two major initiatives to engage their employees in volunteering: Company initiated and organized projects in which employees could participate, and a Company matching program where the company matched the employees volunteering (for a minimum of 25 hours) with a donation to the charity where the employee volunteered. The matching grant program, helps it employees to find their own passions and volunteer in their local communities. It does this by providing $\$ 500$ grants to charities where their employees volunteer for 25 hours or more a year. In 2007, they issued $\$ 70,000$ in such grants. Employees who volunteer to fundraise for a charity can apply to for a grant of up to $\$ 150$ for that charity. The Company initiated programs are usually team based and run on regular basis, although there are some ad hoc projects instated by employees often at the local level. The Company recognizes this volunteer effort and each year selects one employee from around the world for a special award that recognizes the outstanding volunteer contributions of an individual to his or her community

Our findings show that over $90 \%$ respondents participated in only in the companyinitiated projects (92\%), while fewer than two percent participated only in the matching program 
(1.3), and nearly seven percent participated in both programs (6.7\%). Participation levels for ESV programs varied, with the nearly three quarters of the respondents reporting that they participated "occasionally" - a few times a year (74\%), the other quarter having participated weekly $(16 \%)$ or monthly (7\%). Nearly half gave fewer than five hours a month (44\%) and a over a quarter (28\%) gave more than 10 hours a month. Not all volunteering done by the respondents was supported by the Company. Over half (57\%) received full support while $34 \%$ received partial support and $9 \%$ received no support. This suggests that while volunteers in the ESV programs contributed to the social economy and most perceived it as such, it did not preclude them form contributing on an individual level outside the ESV programs. We asked respondents the reason why they chose to volunteer in the ESV programs. Those respondents participating in the ESV programs overwhelmingly said because "it gave them an opportunity to help others", however $60 \%$ also responded that because it was the company culture and $26 \%$ that senior management encouraged participation in ESV programs.

We then examined if ESV programs had any impact on the respondents volunteering behavior.. The most frequently cited outcome, reported by $81 \%$ of volunteers, was getting an opportunity to volunteer with colleagues. Nearly half of the respondents $(42 \%)$ reported that their volunteering through their workplace introduced them to volunteering; a third of the respondents (32\%) even said that it motivated them to volunteer in programs other than those initiated by the company. One in every five (20\%) volunteers reported that the ESV matching program encouraged them to increase the number of hours of volunteering while nearly half $(45 \%)$ of opined that ESV initiatives made no difference in the intensity of their volunteering.

The reasons volunteers gave for volunteering [in general and through ESV programs] and benefits had more to do with their motives to contribute to the social economy versus gaining personal gain or responding to company directives that encourage or expect their employees to volunteer. Although at some level social desirability may give us these results, the on-line survey was confidential, in that only we the researchers, had access to the data that was anonymous. In the company, there is no doubt that ESV programs did create a culture of volunteering and had an impact on why some employees chose to volunteer in the ESV programs.

We gave the respondents a predetermined list of options based on the literature and added some motivations and benefits that reflected the company culture to promote volunteering among it employees. Our findings show respondents ranked as the top two reason, the following: 'to help others' and to contribute to "an important cause'. Interestingly, the "Company expects me to do so" was ranked last. However, some employees wrote in the comments that the "in making volunteering arrangements' the Company helped to identify a 'legitimate, deserving charity'. One wrote as "most of the arrangements are made by the company this is easy and available to fit in my schedule" while another wrote that the Company's "strong support for variety of volunteer 
works, it made easy for us to be involved". The two top rated benefits were "increase a sense of community in society" and "builds trust in society". At the lower end were benefits that were "career enhancement" and "professional networking", and the lowest benefit was "getting recognition from co-workers". This is latter is even more interesting a finding given that $85 \%$ of the respondents said they volunteered alongside their coworkers and colleagues.

Did the company's ESV programs and their participation influence their relations with their employer? Our findings noted that respondents' satisfaction with their workplace improved significantly following their participation in ESV initiatives. Furthermore, employees see company as contributing to the social good and caring for their community and take pride in this image of their company. However, respondents said that ESV programs were less likely to contribute to their retention or loyalty to the company.

In some of the open-ended questions, respondents gave further details on how they perceive the ESV programs. Although not asked directly whether such activities contribute to the social economy, the sentiment is captured in the following quotes:

- "To me it is the XX Public School because it is in our community. I live in the area so it is especially important to me"

- "Giving back to the kids through... The results are seen almost immediately and they directly impact the lives of those around us"

- "Community actives are the most meaningful initiatives by [the Company]"

- "I am proud of what my company does to give back to the community"

- "They always have something we can volunteer in and they are very communityoriented."

- "[The Company] takes active part in community relations and activities"

\section{Conclusions}

The premise of this chapter is that corporate support of employee volunteering constitutes an important and significant contribution to the social economy. While activities engaged in by employees at the encouragement of their employer are documented under the general rubric of corporate social responsibility, they are often hidden from researchers interested in the social economy. Although the purpose of this chapter was not to aggregate the overall impact of the for-profit sector on the social economy, we nevertheless show that certain activities in the forprofit sector are very much part of the social economy. Corporations can and do harness the goodwill of individuals to contribute to the social economy through ESV programs. 
ESV programs have the potential to raise awareness and generate conversations between the various stakeholders in the different sectors that give rise to opportunities for sustained community partnerships. In a period where multinational financial institutions are suspect of creating the largest of financial crises, ESV provides a useful mechanism and a ready channel of communication and engagement with local communities. Employee volunteers give a human face to the institution and lend authenticity and legitimacy to these institutions.

One may argue that social economy activities have no place in the for-profit sector, and that such activity is simply a guise to 'buy' satisfied employees and consumer goodwill. But this is to miss the point. Social economy activities occur in all sectors, and if such activity promotes the social good, then it should not matter whence the spring of goodwill arises. The question then becomes one of efficiency. Is it most efficient for nonprofits to be the predominant promoters of the social good? Or is it government's role to do so? Are ESV and other related activities optimal ways in which the for-profit sector can engage in the social economy and are the many philanthropic and community outreach programs they undertake the most efficient ways of expending resources? Alternatively, should for-profits concentrate on maximizing profits and leave the promotion of social good to government and/or the nonprofit sector?

Increasingly we find nonprofits adopting business models and engaging in profit-making activities (Dart, 2004, Meinhard et al., 2006) and for-profits engaging in the production of social goods through corporate social responsibility programs (Foster et al. 2008) Furthermore, with nonprofits and for-profits engaging in collaborative partnerships, efficiencies might be enhanced as both partners brings their strengths to the collaborations. This notwithstanding, the questions of efficiency in the production of social goods remains contested and unresolved. Until then all activities promoting social good, sector notwithstanding, should be welcomed and taken under the principle of 'do no harm".

\section{References}

Berger, I., Cunningham, P., \& Drumwright, M. (2006). Identity, identification, and relationship through social alliances. Journal of the Academy of Marketing Science, 34(2), 128-37.

Dart, R. (2004). Being 'business-like' in a nonprofit organization: A grounded and inductive typology. Nonprofit and Voluntary Sector Quarterly, 33(2), 290-310.

de Gilder, D.D., Schuyt, T.N.M., \& Breedijk, M. (2005). Effects of an employee volunteering program on the work force. Journal of Business Ethics, 61(2), 143-52. 
Easwaramoorthy, M., Barr, C., Runte, M., \& Basil, D. (2006). Business support for employee volunteers in Canada: Results of a national survey. Retrieved November 13, 2009, from Imagine Canada nonprofitscan.imaginecanada.ca/ imagine_business_support_report.pdf (click here)

Edmans, A. (2009). Does the stock market fully value intangibles? Employee satisfaction and equity prices. Retrieved December 9, 2009, from the Social Science Research Network http://ssrn.com/abstract $=985735$

Foster, M., Meinhard, A., Berger, I., \& Krpan, P. (2009). Corporate philanthropy in the Canadian context: From damage control to improving society. Nonprofit and Voluntary Sector Quarterly, 38(3) 441-66. DOI: 10.1177/0899764008316249.

Graff, L. (2004). Making a business case for employer-supported volunteerism. Retrieved December 9, 2009, from Volunteer Canada www.volunteer.ca/ESVThinkPiece.pdf (click here)

Hall, M., Easwaramoorthy, M., \& Sandler, W. (2007). Business contributions to Canadian communities: Findings from a qualitative study of current practices. Retrieved November 13, 2009, from Imagine Canada nonprofitscan.imaginecanada.ca/business_contributions_en.pdf (click here)

Hall, M., McKeown, L., \& Roberts, K. (2000). Caring Canadians, involved Canadians: Highlights from the 2000 National Survey of Giving, Volunteering and Participating. Retrieved November 13, 2009, from Canadian Centre for Philanthropy givingandvolunteering.ca/n-2000-hr-ca.pdf (click here)

Handy, F., Cnaan, R.A., Brudney, J., Meijs, L., Ascoli, U., \& Ranade, S. (2000). Public perception of 'who is a volunteer': An examination of the net-cost approach - a crosscultural perspective. Voluntas 11(1), 45-65.

Imagine Canada. (2002). Statistics on corporate giving in Canada. Available from www.imagine.ca/content/resource_centre/statistics.asp?section=resources

KPM \& Peat Marwick. (1997). Organizations serving the public: Transformation to the 21st century. New York: KPM \& Peat Marwick.

Meinhard, A., Foster, M., Moher, L., \& Fitzrandolph, S. (2006). Commercial ventures in nonprofit organizations: Strategic change or natural evolution? The Hungarian Journal of Marketing \& Management, 40(6), 147-54. 
Mitchell, W. (2006, June 26). Personal communication.

Mook, L., Quarter, J., \& Richmond, B.J. (2007). What counts: Social accounting for nonprofits and cooperatives. London: Sigel Press.

Moulaert, F., \& Ailenei, O. (2005). Social economy, third sector and solidarity relations: A conceptual synthesis from history to present. Urban Studies, 42(11), 2037-54.

The New York Times Magazine (September 13, 1970). The social responsibility of business is to increase its profits. Retrieved September 13, 2008, from http://www.colorado.edu/studentgroups/libertarians/issues/friedman-soc-respbusiness.html<OK to delete period?>

NSGVP. (2004). Employer-supported volunteering. Retrieved November 13, 2009, from Nonprofitscan GivingandVolunteering.ca/employer_support_volunteering.pdf (click here)

NSNVO. (2005). Cornerstones of community: Highlights of the national survey of nonprofit and voluntary organizations. Ottawa: Minister of Industry.

Orlitzky, M., Schmidt, F., \& Rynes, S. (2003). Corporate social and financial performance: A meta-analysis. Organization Studies, 24(3), 403-41.

Peloza, J., \& Hassay, D.N. (2006). Intra-organizational volunteerism: Good soldiers, good deeds and good politics. Journal of Business Ethics, 64(4), 357-79.

Peloza, J., Hudson, S., \& Hassay, D. (2009). The marketing of employee volunteerism. Journal of Business Ethics, 85(2) 371-86. DOI 10.1007/s10551-008-9734-Z

Points of Light Foundation, Volunteer Center National Network \& The Center for Corporate Citizenship at Boston College. (2005). Measuring employee volunteering programs: The human resources model.

Quarter, J. (1992). Canada's social economy: Co-operatives, non-profits, and other community enterprises. Toronto: James Lorimer.

Quarter, J., Mook, L., \& Armstrong, A. (2009). Understanding Canada's social economy. Toronto: University of Toronto Press. 
Reich, R. (2007). Supercapitalism: The transformation of business, democracy and everyday life. Toronto: Random House of Canada.

Rocha, C. (2009). Developments in national policies for food and nutrition security in Brazil. Development Policy Review27(1), 51-66.

Rochlin, S., \& Christoffer, B. <Christopher in text>(2000). Making the business case: Determining the value of corporate community involvement. The Center for Corporate Citizenship.

Rog, E., Pancer, S.M., \& Baetz, M.C. (2004). Community and corporate perspectives on corporate volunteer programs: A win-win approach to community betterment. Toronto: Canadian Centre for Philanthropy.

Rostami, J., \& Hall, M. (1996). Employee volunteers: Business support in the community. Toronto and Ottawa: Canadian Centre for Philanthropy and Conference Board of Canada.

Safrit, D., \& Merrill, M. (1998, November). An exploratory study of corporate volunteer motivations for baby boomers and Generation X: Critical issues in nonprofit management and leadership. Paper Presented at the 27th Annual Conference of the Association for Research on Nonprofit Organizations and Voluntary Action (ARNOVA), Seattle, WA.

Vaillancourt, Y. (2008). The social economy in contemporary Quebec. In J.J. McMurtry, (Ed.), $<$ ?>Living economics: Perspectives on Canada's social economy. Toronto: Emond Montgomery Publications. 


\section{Notes}

${ }^{1}$ The authors note that 'the most common forms of [volunteer] support are adjusting work schedules (78\%), providing time-off without pay (71\%), and allowing access to company facilities and equipment (70\%)' (p. iii).

${ }^{2}$ Subsection 459.3(1) of the Bank Act; Public Accountability Statements (Banks, Insurance Companies, Trust and Loan Companies) Regulations P.C. 2002-402 March 21, 2002. http://laws.justice.gc.ca/en/ShowDoc/cr/SOR-2002-133/bo-ga:s_1::boga:s_2//en?page=1\&isprinting=true

${ }^{3}$ These figures are not mutually exclusive, as respondents could reply positively to more than one option. 